\title{
Assemblages of Culturable Airborne Fungi in a Typical Urban, Tourism-driven Center of Southeast China
}

\author{
Zhiguo Fang $^{1 *}$, Junwen Zhang ${ }^{1}$, Weijun Guo ${ }^{1}$, Xiuqin Lou ${ }^{2}$ \\ ${ }^{1}$ School of Environmental Science and Engineering, Zhejiang Gongshang University, Hangzhou 310012, China \\ ${ }^{2}$ Hangzhou Center for Disease Control and Prevention, Hangzhou, 310021, China
}

\begin{abstract}
Assessing the prevalence of airborne fungi in a city or region is critical to diagnosing the ecology and effectively treating allergic manifestations induced by inhaling fungal allergens. The present study was conducted to evaluate the characteristics and variations of culturable airborne fungi at four selected sampling sites in Hangzhou in southeastern China. Results showed that the concentration of culturable fungi in the air ranged from $<12$ colony forming units CFU $\mathrm{m}^{-3}$ to $8767 \mathrm{CFU} \mathrm{m}^{-3}$ with a mean of $848 \mathrm{CFU} \mathrm{m}^{-3}$. We identified a total of 352 fungal isolates from multiple sampling sites and across seasons, which were distributed among 21 genera and 85 species of fungi. Penicillium, Cladosporium, Alternaria, Aspergillus, and Trichoderma were the most predominant fungi, based on frequency and concentration, and the fungal composition differed both between sites and between seasons. Approximately $36.5 \%$ of the total number of isolated fungal species belonged to Penicillium, which also contributed the largest proportion of the total fungal concentration (about 29.6\%). The most prevalent fungal species in Hangzhou were P. chrysogenum (7.7\%), C. cladosporioides (6.3\%), Alternaria alternata (5.6\%), P. funiculosum (4.3\%), and Aspergillus sydowii (4.0\%). Moreover, significant variation existed between the sampling sites, with the highest fungal concentrations detected on Zhejiang Gongshang University Jiaogong Campus (ZJGSUJC) and Breeze-ruffled Lotus at Quyuan Garden (BLQG), followed by those on Yan'an Road Business Street (YRBS). The lowest concentrations $(P<0.05)$ were found on Tianmushan and Jiaogong Cross Road (TJCR). Furthermore, the concentrations at the four sites exhibited different seasonal patterns, with the lowest mean concentrations occurring during winter at all of the locations, whereas no difference was detected between summer, autumn, and spring. Our results provide a baseline for studying culturable airborne fungi in southeastern China, thus allowing the health risks from exposure to the atmosphere to be evaluated.
\end{abstract}

Keywords: Penicillium; Cladosporium; Airborne fungi; Species composition; Concentration distribution.

\section{INTRODUCTION}

Bioaerosols, well known normal components in the air, contain microorganisms and their components such as fungi, bacteria, endotoxin, mycotoxins, and allergens (Kim et al., 2018). Undoubtedly, airborne fungi constitute a significant and dominant part of global bioaerosols and belong to the coarse fraction of air particulate matter (Sesartic and Dallafior, 2011). On one hand, airborne fungi have a potential role in regulating atmospheric chemistry and modulating climate by acting as ice and cloud condensation nuclei (Ariya et al., 2009; Fröhlich-Nowoisky et al., 2009; Sesartic et al., 2013). On the other hand, fungi in the air

\footnotetext{
* Corresponding author.

Tel.: +86-571-28008213; +86-571-15988876720;

Fax: +86-571-28008215

E-mail address: zhgfang77@zjgsu.edu.cn
}

can damage building materials in humid conditions, and they can also invade and infect living organisms (Eduard, 2009; Salonen et al., 2015a). Furthermore, fungi and their by-products are significant causes of adverse effects on human health such as respiratory disorders, hypersensitivity pneumonitis, and toxic reactions (Gorny et al., 2002; Fracchia et al., 2006), and exposure to fungi may lead to allergic sensitization and symptoms of allergies and asthma (Stark et al., 2005; Park et al., 2006). Generally, more than 80 genera of fungi have been associated with symptoms of respiratory tract allergies, and over 100 species have been implicated in serious human and animal infections (Horner, 2004).

The adverse health effects of fungi have been studied globally, and many studies have assessed the presence of airborne fungi in different environments (Shelton et al., 2002; Adhikari et al., 2004; Fang et al., 2005; Zuraimi et al., 2009; Wang et al., 2011; Salonen et al., 2015b; Li et al., 2015). These results have significantly enriched our baseline knowledge of fungal characteristics in the atmosphere, and supported many applications related to public health and 
international security. However, such studies face significant challenges, as the high number of factors that can influence fungi (such as seasonal effects, local climate, weather patterns, and human activities) might lead to enormous differences in the community of airborne fungi found in different regions (Jones and Harrison, 2004; Kalyoncu, 2010). Therefore, it is necessary to collect detailed information about airborne fungi from different environments with typical characteristics, and to better understand fungal distributions.

Hangzhou, the capital and largest city of Zhejiang Province in China, has a subtropical monsoon climate with four distinctive seasons, a warm winter and hot summer, and abundant precipitation. Impressively, Hangzhou has one of the most popular attractions in southeastern China, West Lake, and is also regarded as one of the most desirable cities to inhabit in China. After hosting the G20 summit in 2016, Hangzhou is attracting more and more tourists, and the number of tourists in Hangzhou has increased consistently. Since there is still little known about the characteristics, concentration, and distribution of airborne fungi in a typical tourist city of southeastern China, we chose Hangzhou as a model location for measuring culturable airborne fungi. The main objective of the study was to describe the group and concentration variation pattern of culturable airborne fungi in Hangzhou in a detailed, systemic manner.

\section{MATERIALS AND METHODS}

\section{Description of Sampling Sites}

Hangzhou, a world-famous city in southeast China, was selected as the location for airborne fungal sampling in this study. Four typical sampling sites were selected for this study based on their urban function (Fang et al., 2005, 2007): (1) Tianmushan and Jiaogong Cross Road (TJCR), a heavily trafficked intersection located in Xihu District about $3 \mathrm{~km}$ from the city center; (2) Zhejiang Gongshang University Jiaogong Campus (ZJGSUJC), a cultural and educational area situated in Xihu District about $4 \mathrm{~km}$ from the city center; (3) Yan'an Road Business Street (YRBS), a commercial area and business district located at the center of Hangzhou and in Xiacheng District; and (4) Breezeruffled Lotus at Quyuan Garden (BLQG), a scenic tourist area situated in Xihu District near West Lake, and about 5 $\mathrm{km}$ from the city center. Detailed information about these selected sites can be found in Table 1 .

\section{Sampling Design and Methods}

We used an FA-1 sampler (imitation Andersen sampler, fabricated by the Applied Technical Institute of Liaoyang, China) for the collection of culturable airborne fungi (Fang et al., 2005). Each stage of the airborne fungal sampling included a plate with 400 holes of uniform diameter, through which air was drawn at $28.3 \mathrm{~L} \mathrm{~min}^{-1}$ before coming into contact with nutrient agar-filled petri dishes. Airborne particles were separated into six fractions according to the following aerodynamic cut-size diameters: $7.0 \mu \mathrm{m}$ (Stage 1), 4.7-7.0 $\mu \mathrm{m}$ (Stage 2), 3.3-4.7 $\mu \mathrm{m}$ (Stage 3), 2.1-3.3 $\mu \mathrm{m}$ (Stage 4), 1.1-2.1 $\mu \mathrm{m}$ (Stage 5), and 0.65-1.1 $\mu \mathrm{m}$ (Stage 6). The FA-1 sampler was sterilized in a hot air oven at $180^{\circ} \mathrm{C}$

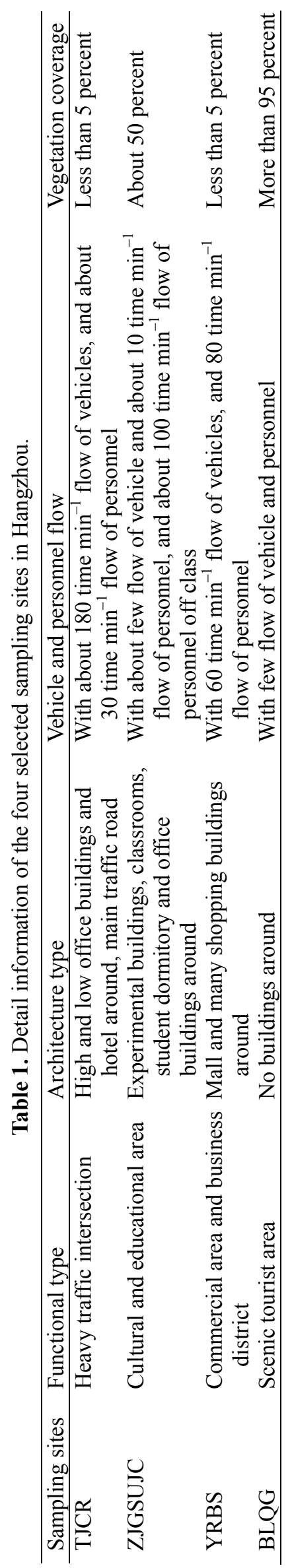


for $2 \mathrm{~h}$ before each $24 \mathrm{~h}$ measurement, and subsequently washed with $5 \%$ bleach and $70 \%$ ethanol solution at the sampling site prior to next collection.

Fungal sampling in the air was conducted at four sampling sites throughout Hangzhou from July 2014 to June 2015. Sampling devices were operated at a sampling flow rate of $28.3 \mathrm{~L} \mathrm{~min}^{-1}$, and maintained with a platform at a height of $\sim 1.5 \mathrm{~m}$. Air samples were collected for $3 \mathrm{~min}$ in triplicate, three times daily (09:00, 13:00, and 17:00), for three consecutive days of each month of the year. For each air sampling event, the FA-1 sampler was loaded with $9.0 \mathrm{~cm}$ petri dishes containing Sabouraud agar with chloramphenicol to inhibit bacterial growth. Exposed culture dishes were incubated for $72 \mathrm{~h}$ at $25^{\circ} \mathrm{C}$.

\section{Enumeration of Fungi}

After incubation, the fungal colonies were counted, and the concentration of the samples was expressed as CFU per cubic meter of air $\left(\mathrm{CFU} \mathrm{m}^{-3}\right)$. However, since superposition is unavoidable when the microbial particles impact the same spot through the same sieve pore, the number of colonies was recalculated using Macher's method (Macher, 1989; Fang et al., 2007). Fungal concentration was recorded as $<12$ if the total colonies collected with the sampler were less than one.

\section{Fungal Identification}

After incubation and counting, the fungal colonies growing on each dish were identified microscopically to the genus level, based on the morphology of observed hyphae, conidia, and sporangia. Fungal colonies that were subcultured onto malt extract agar but had not developed sporing structures after 14 days were described as "non-sporing isolates." The fungal isolates were then identified further using the molecular method described below. Each pure isolate was homogenized in liquid culture medium, and DNA was extracted using the cetyltrimethylammonium bromide method (Möller et al., 1992). The internal transcribed spacer (ITS) region of the fungal rRNA genes was amplified using the following universal primer set: ITS $_{1}$ (5'-TCCGTAGGTGAACCTGCGG-3') and ITS $_{4}$ (5'TCCTCCGCTTATTGATATGC-3') (White et al., 1990; Wang et al., 2011). The reaction mixture $(50 \mu \mathrm{L})$ consisted of $0.3 \mu \mathrm{L}$ Taq polymerase, $2 \mu \mathrm{L}$ dNTP, $5 \mu \mathrm{L} 10 \times$ polymerase chain reaction (PCR) buffer, $2 \mu \mathrm{L}$ of each primer, and $1.0 \mu \mathrm{L}$ (ca. $10 \mathrm{ng}$ DNA) of template. The amplification program was as follows: initial denaturation at $94^{\circ} \mathrm{C}$ for $5 \mathrm{~min}, 30$ cycles of $94^{\circ} \mathrm{C}$ for $30 \mathrm{~s}$, annealing at $55^{\circ} \mathrm{C}$ for $30 \mathrm{~s}$, extension at $72^{\circ} \mathrm{C}$ for $30 \mathrm{~s}$, followed by a final extension at $72^{\circ} \mathrm{C}$ for $10 \mathrm{~min}$. The PCR products were detected using electrophoresis on a $1 \%$ agarose gel. The sequences were obtained by the Beijing Genomics Institute, China, and were analyzed with the BLAST program of the National Center for Biotechnology Information, USA (http://www.ncbi.nlm. nih.gov/Blast.cgi). Sequences showing the highest similarity to those of the clones were extracted from GenBank.

\section{Statistical Analysis}

All experimental data were analyzed with the software programs Excel 2010 and SPSS Version 19.0 (Standard Version, SPSS Inc.). Descriptive statistics were calculated to summarize fungal concentrations (including mean, median, and geometric mean concentration). The data for airborne fungal concentration were normally distributed; one-way analysis of variance (ANOVA) was used to compare different sampling sites and sampling times, followed by Tukey and Duncan post hoc tests.

\section{RESULTS}

\section{Fungal Groups and Characterization of Variation Description of Fungal Taxa}

A total of 352 fungal isolates belonging to 21 genera and 85 species of culturable airborne fungi were identified from the four selected sampling sites in Hangzhou (Fig. 1). The fungal genera that appeared with high frequency were Penicillium (31.0\%), Cladosporium (13.6\%), Aspergillus (10.5\%), Alternaria (6.5\%), Trichoderma (6.3\%), Phoma (4.6\%), and Eurotium (3.4\%), and all these dominant fungal genera accounted for $75.9 \%$ of the total isolates. As for fungal species, P. chrysogenum (7.7\%), C. cladosporioides (6.3\%), Alternaria alternata (4.6\%), P. funiculosum (4.3\%), and Aspergillus sydowii (4.0\%) were prevalent, followed by $C$. tenuissimum (2.3\%), Alternaria tenuissima $(2.0 \%)$, and Aspergillus nidulans (2.0\%) at lower rates. Numerous other fungal species identified were observed less frequently. Moreover, approximately $36.5 \%$ (31 species) of the total number of species belonged to the genus Penicillium. A further 7 species of Aspergillus (8.2\%), 6 species each of Cladosporium and Phoma (7.1\%), and 5 species of Trichoderma $(5.9 \%)$ were identified in the fungal samples.

\section{Fungal Groups among Sampling Sites}

Fig. 2 demonstrates the frequency and concentration percentage $(\%)$ of culturable airborne fungi at different sampling sites in Hangzhou. A higher frequency at selected sampling sites was identified for Penicillium, Mycelia sterilia, Cladosporium, Alternaria, and Aspergillus. The maximum concentration percentages of Penicillium detected were $32.7 \%, 31.0 \%, 28.8 \%$, and $25.9 \%$ at the sampling sites TJCR, YRBS, ZJGSUJC, and BLQG, respectively. While the higher concentration percentages of Penicillium occurred at TJCR and YRBS, by contrast, the lower concentration percentages of Alternaria were also observed at those sites, with $10.0 \%$ at TJCR, and $9.6 \%$ at YRBS. The lowest concentration percentage of Cladosporium was $19.0 \%$ observed at TJCR. Finally, higher concentration percentages of Aspergillus were found at TJCR (8.1\%) and YRBS (8.6\%) than at ZJGSUJC (6.7\%) and BLQG (7.6\%).

\section{Fungal Groups across Seasons}

Fig. 3 demonstrates the frequency and concentration percentage of culturable airborne fungi across different seasons in Hangzhou. A higher frequency across different seasons was observed for Penicillium, Cladosporium, Mycelia sterilia, Aspergillus, and Alternaria. In winter, the frequency of airborne fungi was much lower than those of other seasons in a year. Penicillium had the maximum 

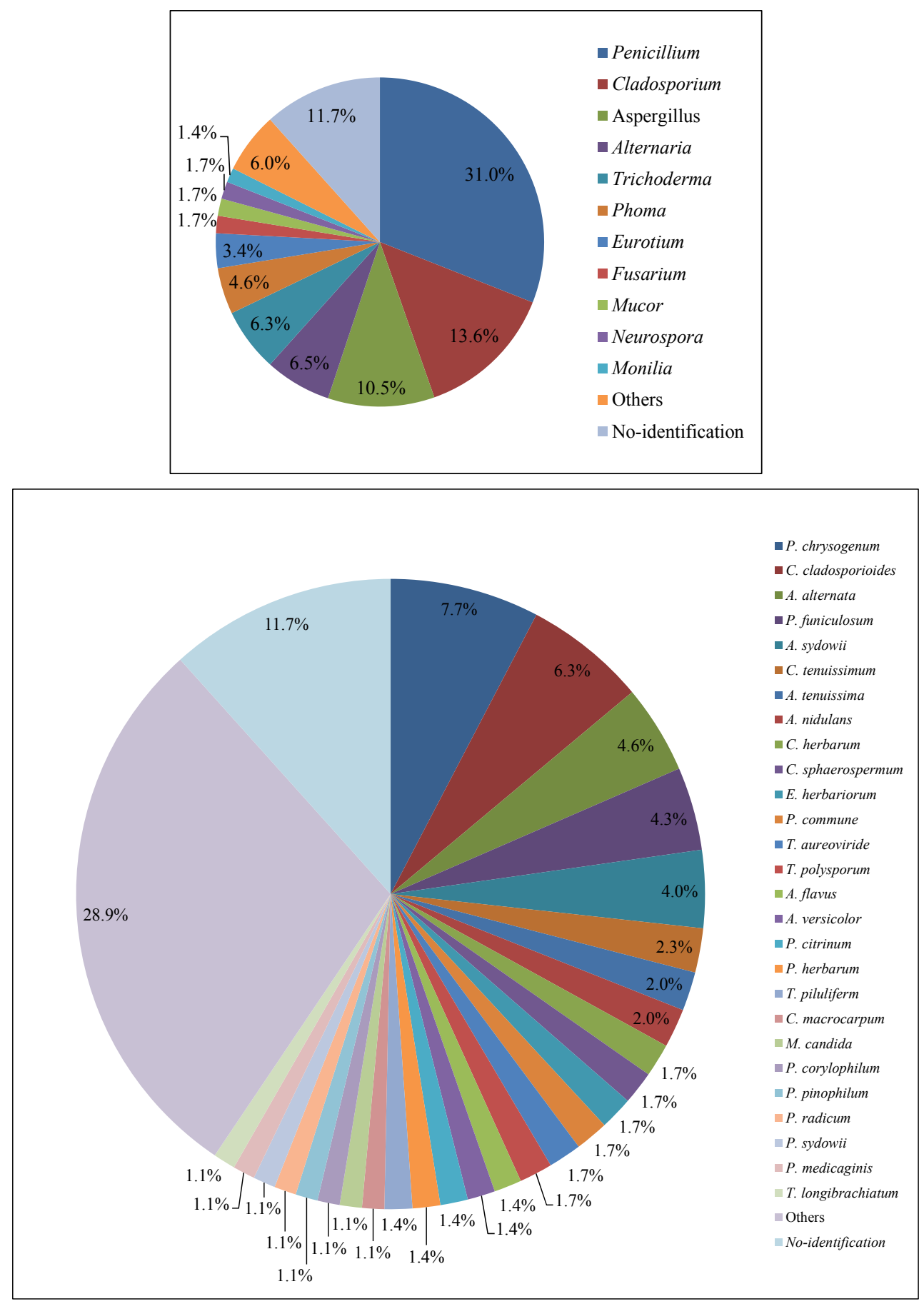

Fig. 1. The percentage of isolated airborne fungal genera and species identified at the selected sampling sites in Hangzhou.

fungal concentration percentage in all four seasons, accounting for $28.5 \%, 29.2 \%, 29.4 \%$, and $28.9 \%$ in spring, summer, autumn, and winter, respectively. Cladosporium was the second most concentrated group isolated from the samples, followed by Alternaria, non-sporing isolates, and Aspergillus. Their concentration percentages varied from $7.1 \%$ to $24.6 \%$. Additionally, a higher concentration percentage of Cladosporium was observed in autumn and winter than in spring and summer $(P<0.05)$, while there were no seasonal differences in concentration percentage of Penicillium $(P>0.05)$. The highest and lowest concentration percentages of Alternaria were observed in winter and spring $(P<0.05)$, respectively, whereas those of Aspergillus were higher in spring and summer $(P<0.05)$.

\section{Fungal Concentration and Variation \\ Overall Fungal Concentration}

Fungal concentrations varied greatly among different sampling sites across Hangzhou, ranging from $<12 \mathrm{CFU} \mathrm{m}^{-3}$ to $8767 \mathrm{CFU} \mathrm{m}^{-3}$. The mean and median fungal concentrations were approximately $848 \pm 193 \mathrm{CFU} \mathrm{m}^{-3}$ and $550 \mathrm{CFU} \mathrm{m}^{-3}$ (Fig. 4). 

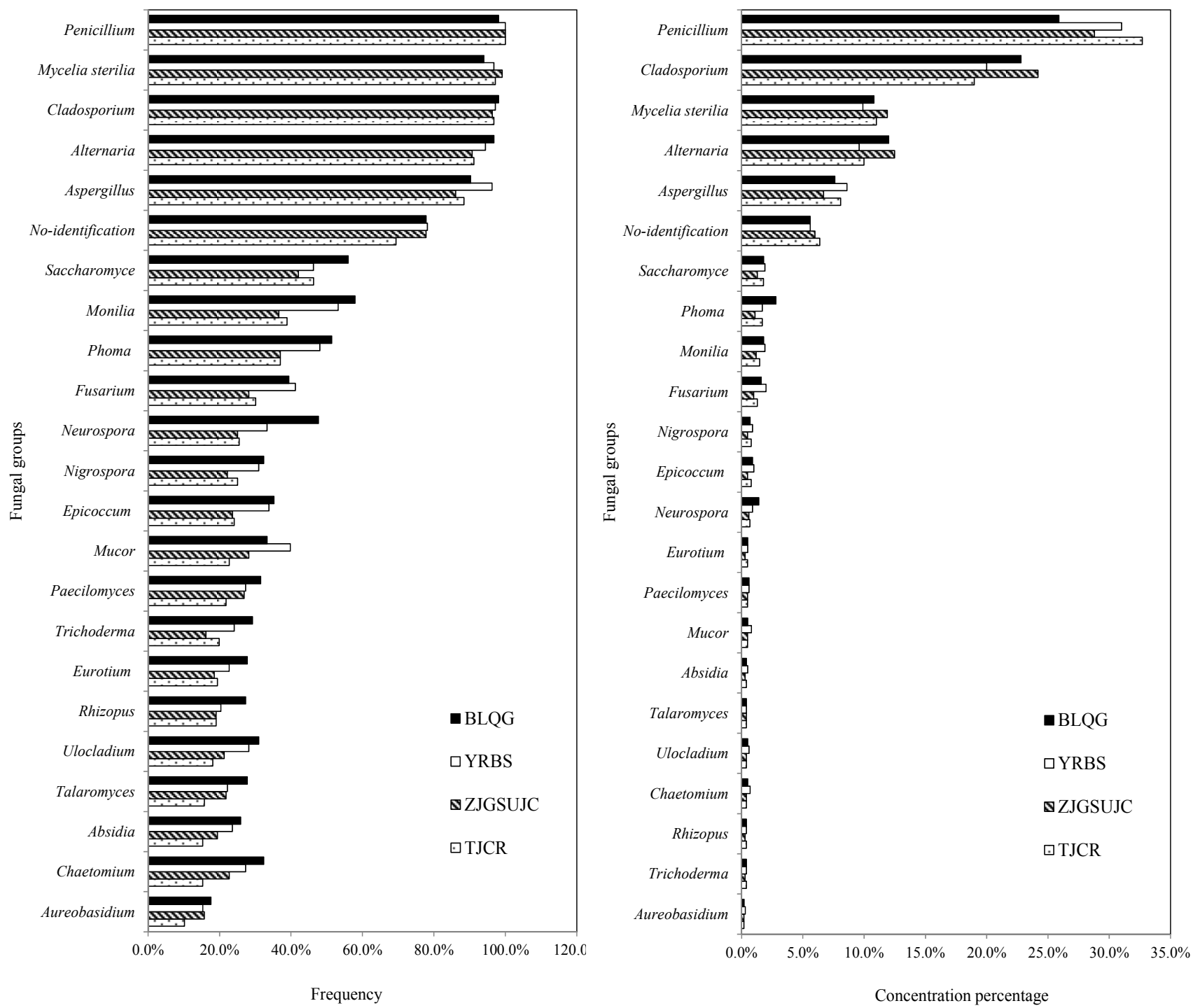

Fig. 2. Spatial variation of culturable airborne fungal frequency and concentration percentage at four selected sampling sites in Hangzhou.

\section{Spatial Variation of Fungal Concentration}

Fungal concentrations from the different sampling sites are demonstrated in Fig. 4. Significantly higher concentrations were measured at ZJGSUJC and BLQG, followed by YRBS, and the lowest concentrations were found at TJCR $(P<0.05)$. No significant differences in fungal concentrations were detected between ZJGSUJC and BLQG $(P>0.05)$. The mean concentrations were as follows: ZJGSUJC (1176 $\left.\pm 91 \mathrm{CFU} \mathrm{m}^{-3}\right)$, BLQG $\left(939 \pm 74 \mathrm{CFU} \mathrm{m}^{-3}\right)$, YRBS $(719 \pm$ $\left.43 \mathrm{CFU} \mathrm{m}^{-3}\right)$, and TJCR $\left(557 \pm 28 \mathrm{CFU} \mathrm{m}^{-3}\right)$.

\section{Temporal Variation of Fungal Concentration}

Seasonal Variation of Fungal Concentration

The mean fungal concentration from all four sites was lowest during the winter $\left(368 \mathrm{CFU} \mathrm{m}^{-3}\right)$, with no differences among the other seasons of summer $\left(1003 \mathrm{CFU} \mathrm{m}^{-3}\right)$, autumn (1068 CFU m ${ }^{-3}$ ), and spring (952 CFU m $\mathrm{C}^{-3}$ ). Individually, the highest fungal concentrations from TJCR and YRBS were observed in the autumn, followed by spring and summer, and they were the lowest during the winter $(P<0.05)$. Similarly, the lowest fungal level was found during the winter at ZJGSUJC and BLQG, but there was no difference in fungal concentration among the other seasons at either location $(P>0.05)$ (Fig. 5).

\section{Monthly Variation of Fungal Concentration}

The highest fungal concentrations among all four sites combined were observed in June (1641 CFU m${ }^{-3}$ ), July (1649 CFU m ${ }^{-3}$ ), October (993 CFU m ${ }^{-3}$ ), and November $\left(1268 \mathrm{CFU} \mathrm{m}^{-3}\right)$, while the lowest concentrations were in January (489 CFU m ${ }^{-3}$ ), February (357 CFU m ${ }^{-3}$ ), March $\left(257 \mathrm{CFU} \mathrm{m}^{-3}\right)$, and April (342 $\left.\mathrm{CFU} \mathrm{m}^{-3}\right)$. When each site was analyzed individually, the fungal concentrations within TJCR were highest from June to July and from October to December compared to other months of the year $(P<0.05)$; the highest concentration was in November $\left(856 \mathrm{CFU} \mathrm{m}^{-3}\right)$ and the lowest was during March $\left(241 \mathrm{CFU} \mathrm{m}^{-3}\right.$ ). For the ZJGSUJC site, higher concentrations were found during 

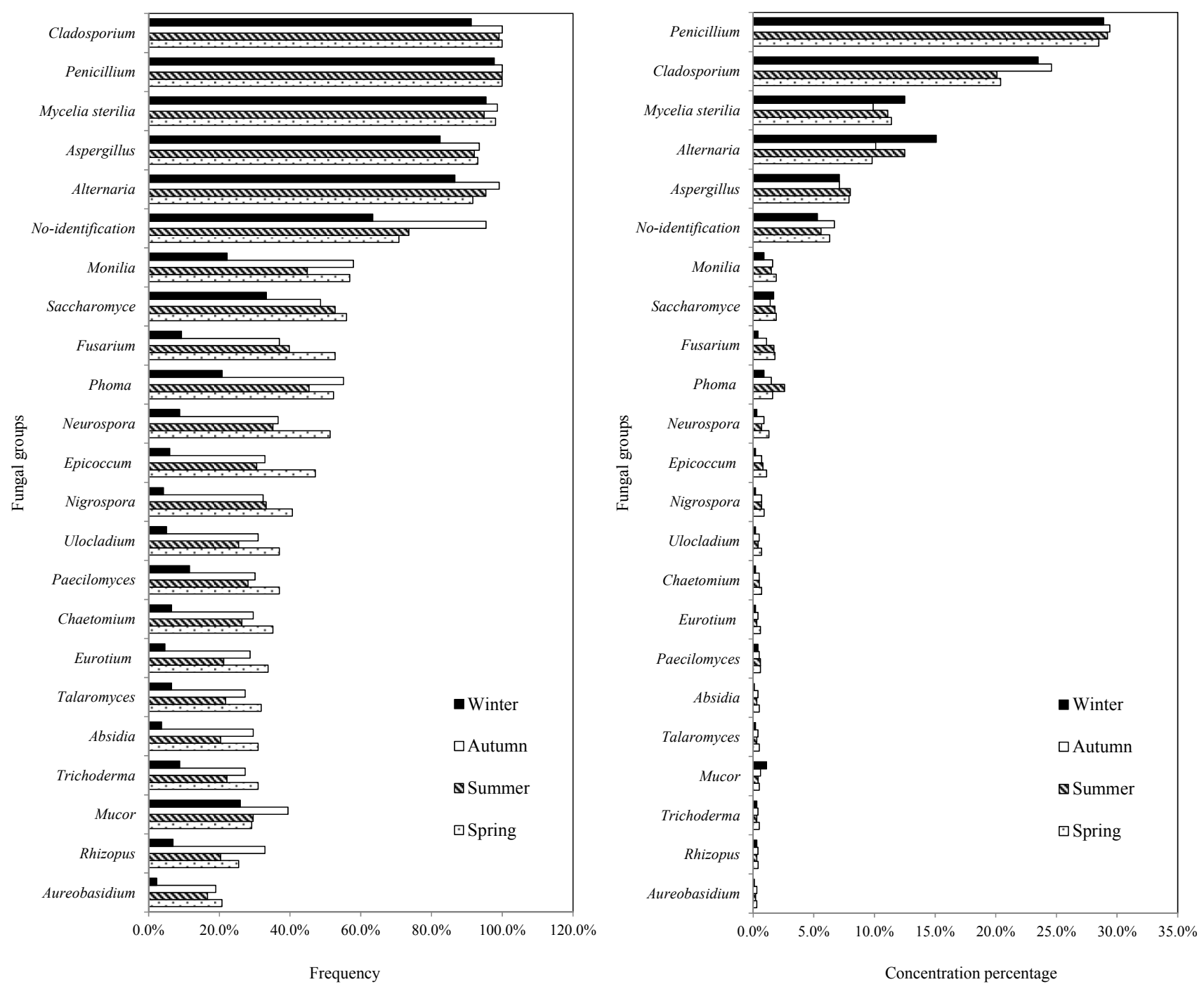

Fig. 3. Seasonal variation of culturable airborne fungal frequency and concentration percentage at four selected sampling sites in Hangzhou.

June $\left(2661 \mathrm{CFU} \mathrm{m}^{-3}\right)$ and July $\left(2674 \mathrm{CFU} \mathrm{m}^{-3}\right)$, while the lowest concentrations were in March $\left(208 \mathrm{CFU} \mathrm{m}^{-3}\right)$ and April $\left(314 \mathrm{CFU} \mathrm{m}^{-3}\right)$. Within BLQG, the fungal concentrations during June $\left(2143 \mathrm{CFU} \mathrm{m}^{-3}\right)$ and July $(2307$ $\mathrm{CFU} \mathrm{m}{ }^{-3}$ ) were the highest, and February $\left(364 \mathrm{CFU} \mathrm{m}^{-3}\right)$ and March $\left(260 \mathrm{CFU} \mathrm{m}^{-3}\right)$ were the lowest. Finally, higher fungal concentrations were detected at YRBS during October (1113 $\mathrm{CFU} \mathrm{m}^{-3}$ ), December $\left(1283 \mathrm{CFU} \mathrm{m}^{-3}\right)$, and May $\left(1008 \mathrm{CFU} \mathrm{m}^{-3}\right)$, and the lowest were during March $\left(321 \mathrm{CFU} \mathrm{m}^{-3}\right.$ ) and April (331 $\mathrm{CFU} \mathrm{m}^{-3}$ ) (Fig. 6).

Fungal Concentration of Three Time Points in a Day

Fungal concentration of three time points in a day at four selected sampling sites in Hangzhou was demonstrated in Fig. 7. In total, significantly higher fungal concentrations were recorded at 09:00 and 17:00 as compared to 13:00 $(P<0.05)$. However, there was no difference in fungal concentrations among times of day at BLQG, while they were lowest at 13:00 $(P<0.05)$ at each of the other sites (TJCR, ZJGSUJC, and YRBS).

\section{Correlation between Environmental Parameters and Fungal Concentration}

Data from all sampling sites demonstrated that air temperature influenced positively $(P<0.01)$ the total fungal count and the genera of Penicillium and Aspergillus $(P<0.01)$, and a significantly positive correlation between relative humidity and concentration of total fungi and Penicillium was also found $(P<0.01)$. Interestingly, air temperature and relative humidity affected significantly and positively the concentration of total fungi, Penicillium, Alternaria, Aspergillus, Cladosporium, and non-sporing isolates at the sampling site of BLQG $(P<0.01)$ (Table 2).

\section{DISCUSSION}

Airborne fungi are among the most common organisms in nature and are correlated with adverse health effects on humans and plants (Shelton et al., 2002). Penicillium, Alternaria alternata, and Closporium herbarum are likely to cause allergies, and types such as Stachybotris, 


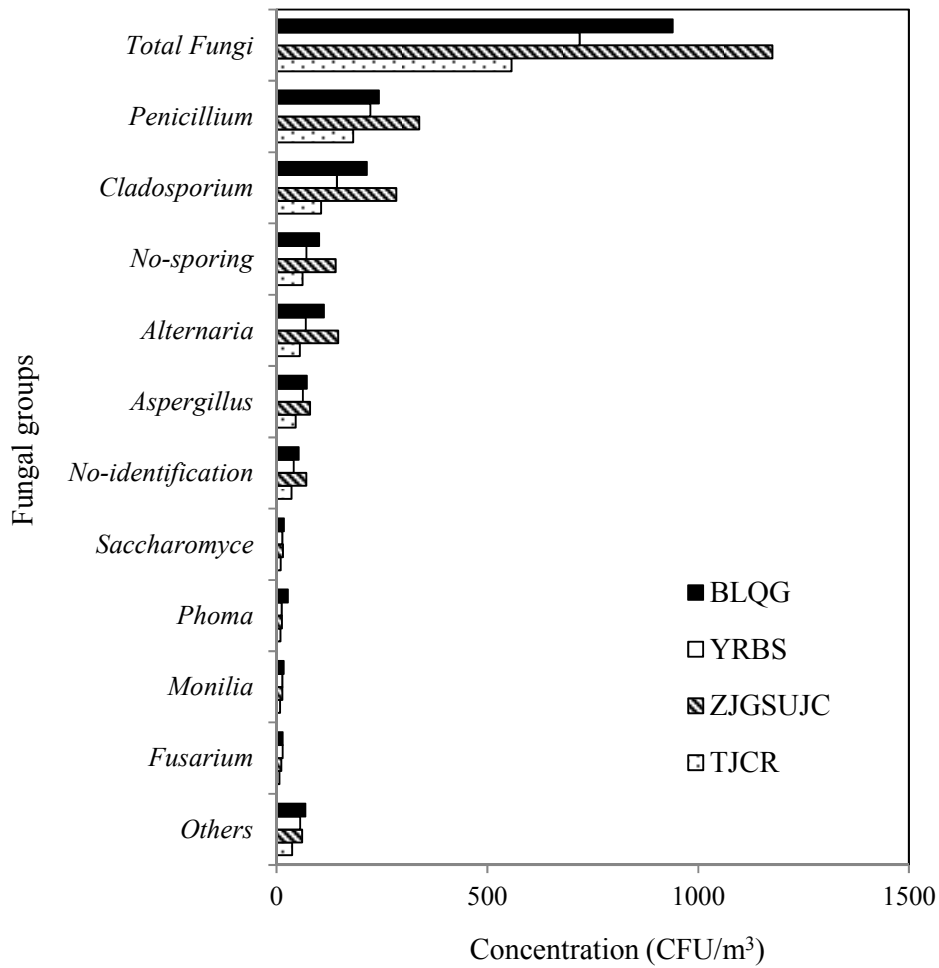

Fig. 4. Mean concentration of dominant airborne fungi at different sampling sites in Hangzhou.

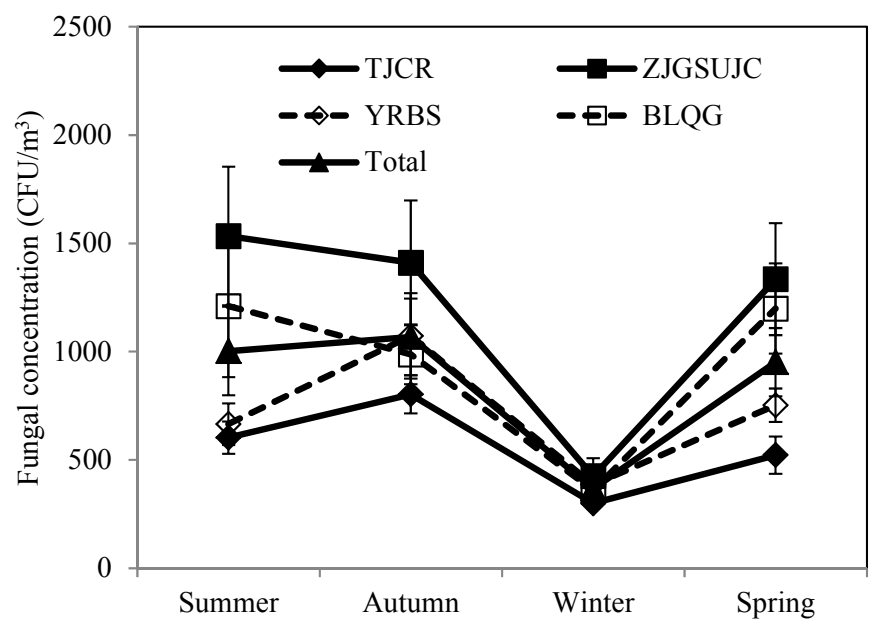

Fig. 5. Seasonal variation of airborne fungal concentration at different sampling sites in Hangzhou.

Trichoderma, Fusarium, and Aspergillus flavus can produce mycotoxins that are harmful to humans, while Mucor and Rhizopus can cause high rates of infection (Garrett et al., 1998; Dillon et al., 1999; Bush et al., 2006). In the present study, Penicillium, Cladosporium, Aspergillus, Alternaria, and Trichoderma were determined as the predominant fungal genera in the atmosphere of Hangzhou, and their respective compositions appeared to differ between sampling sites and seasons. Our results were basically in accordance with other reports, such as the finding that Cladosporium, Penicillium, Aspergillus, and Alternaria spores were constantly present in the atmosphere of Dublin (O'Gorman et al., 2008). In the Helwan area of Egypt, Aspergillus,
Penicillium, Alternaria, and Cladosporium were the most predominant airborne fungal genera (Abdel Hameed et al., 2009), and Cladosporium, Penicillium, and Aspergillus were the dominant genera in the Austrian state of Styria (Haas et al., 2014). In Turkey's Manisa, Cladosporium was the most dominant fungal genus, followed by Penicillium, Aspergillus, and Alternaria (Kalyoncu et al., 2008). From 1993 to 2013 in Sagamihara, the most common fungi except for yeasts and sterile mycelium were Cladosporium, Alternaria, and Penicillium etc. (Saito et al., 2015). Altogether, these results suggest that the dominant culturable fungal genera in the atmospheres of different regions are almost the same, but the specific percentages 

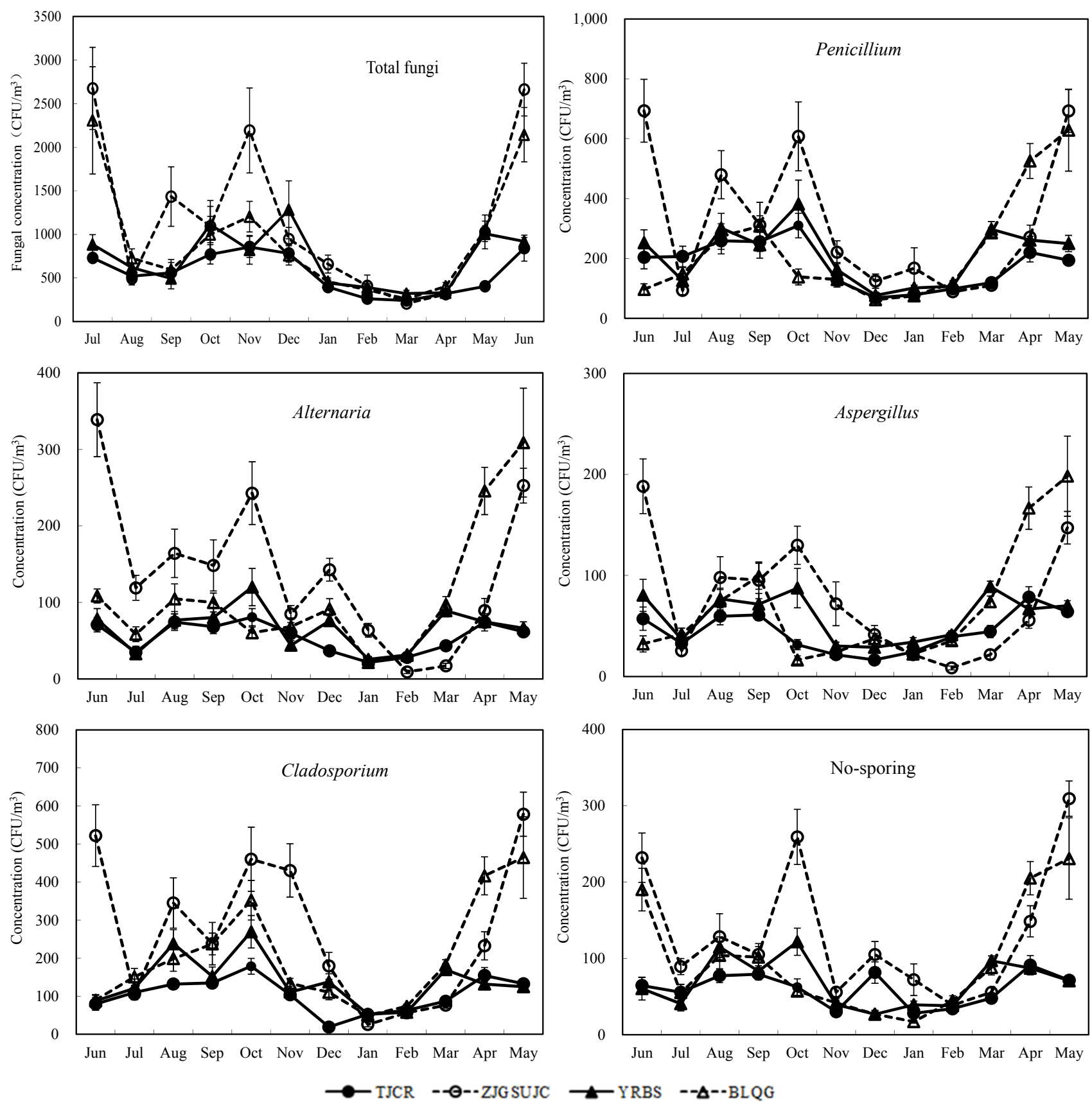

Fig. 6. Monthly variation of airborne fungal concentration at different sampling sites in Hangzhou.

vary tremendously by district due to major differences in meteorological factors, geographical location, air pollutants, human activity, and fungal growth substrates (Tang, 2009; Abdel Hameed et al., 2012; Gao et al., 2016; Pyrri et al., 2017). Previously, we found that Cladosporium was the most dominant fungal genus in the atmosphere of Beijing in northern China (Fang et al., 2005). In this study, the most abundant fungi in Hangzhou in southeastern China were Penicillium. Without a doubt, different kinds of fungi require different environments for growth. Cladosporium are usually found in higher concentrations in dry regions due to their dry-weather spores, whereas Penicillium are equipped with small dry conidia, which can be liberated by even slight air currents or vibrations and thus serve as a passive launching mechanism (Lin et al., 2000; Abdel Hameed, et al., 2009). Beijing, a typical urban center of northern China, is located in a warm temperate zone with a semi-humid continental monsoon climate and an average annual rainfall of about $600 \mathrm{~mm}$. Hangzhou, a typical urban center of southeastern China, is situated in an area with a subtropical monsoon climate and an average annual rainfall of 1100 to $1600 \mathrm{~mm}$. These climate characteristics might be the critical factors driving the higher fungal percentage of Penicillium in Hangzhou compared to Beijing.

Additionally, the amount and type of vegetation coverage strongly influences the concentrations of the outdoor 


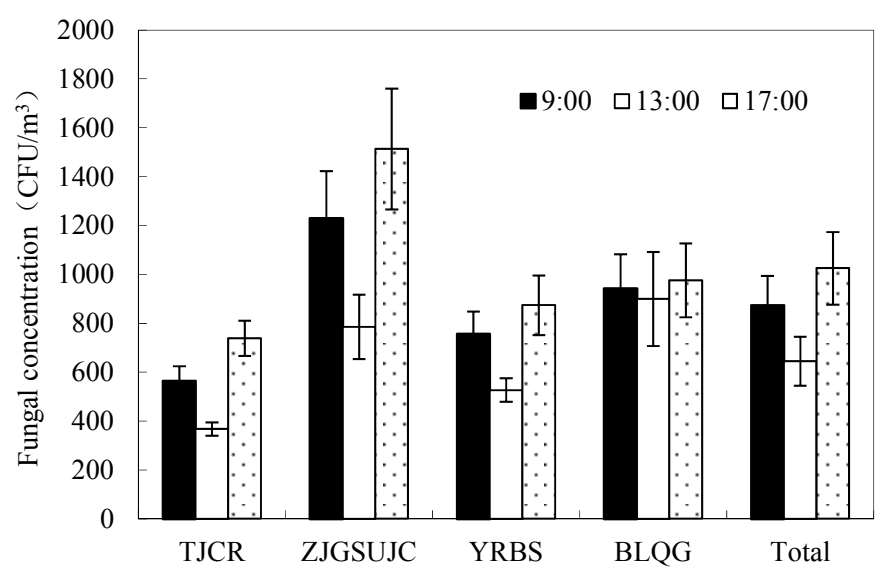

Fig. 7. Fungal concentration of three time points in a day at different sampling sites in Hangzhou.

Table 2. Correlation between environmental parameters and individual/total fungal species concentration at different sampling sites.

\begin{tabular}{llll}
\hline Sampling sites & Fungal concentration & Air temperature & Relative humidity \\
\hline ZJGSUJC & Total fungi & $0.330^{* *}$ & $0.497^{*}$ \\
& Penicillium & $0.350^{* *}$ & $0.246^{*}$ \\
& Alternaria & $0.364^{* *}$ & 0.156 \\
& Aspergillus & $0.355^{* *}$ & 0.133 \\
Cladosporium & 0.206 & 0.202 \\
& Non-sporing isolates & $0.362^{* *}$ & $0.323^{* *}$ \\
& Total fungi & $0.334^{* *}$ & $0.267^{* *}$ \\
& Penicillium & $0.316^{* *}$ & $0.225^{*}$ \\
& Alternaria & 0.222 & 0.177 \\
& Aspergillus & $0.420^{* *}$ & $0.335^{* *}$ \\
YRBS & Cladosporium & $0.260^{*}$ & $0.238^{*}$ \\
& Non-sporing isolates & 0.220 & 0.163 \\
& Total fungi & $0.258^{*}$ & $0.277^{*}$ \\
& Penicillium & $0.265^{*}$ & $0.288^{* *}$ \\
& Alternaria & 0.142 & 0.210 \\
BLQG & Aspergillus & $0.304^{* *}$ & $0.274^{*}$ \\
& Cladosporium & 0.114 & 0.024 \\
& Non-sporing isolates & $0.271^{*}$ & 0.206 \\
& Total fungi & $0.359^{* *}$ & $0.351^{* *}$ \\
& Penicillium & $0.318^{* *}$ & $0.370^{* *}$ \\
& Alternaria & $0.328^{* *}$ & $0.318^{* *}$ \\
& Aspergillus & $0.312^{* *}$ & $0.329^{* *}$ \\
& Cladosporium & $0.253^{* *}$ & $0.235^{*}$ \\
& Non-sporing isolates & $0.481^{* *}$ & $0.322^{* *}$ \\
\hline
\end{tabular}

* represents $p<0.05$ (2-tailed), ${ }^{* *}$ represents $p<0.01$ (2-tailed).

airborne fungi in a given area. Among the four sites that we sampled in Hangzhou, ZJGSUJC and BLQG displayed significantly higher bacterial concentrations, followed by YRBS, while TJCR exhibited the lowest concentration $(P$ $<0.05$ ). These results are in full accordance with our previous studies, which demonstrated that the concentration of airborne fungi in greener areas was significantly higher than in densely urban and highly trafficked areas (Fang et al., 2005), and also agree with other published findings that show green areas with multiple trees, shrubs, and herbaceous plants have much higher fungal concentrations (Ju et al., 2003), since phylloplanes (i.e., leaf surfaces) allow several saprophytic and parasitic fungi to grow (Picco et al., 2000). Therefore, our present results offer further confirmation that areas with high vegetation coverage also have higher levels of airborne fungi.

Weather conditions are another significant factor affecting the airborne fungal concentrations in outdoor environments. Indeed, we found that the total fungal concentrations at all four sites were lowest during winter, with no difference between the other seasons. However, in Beijing, the fungal concentrations were higher in summer and autumn than in winter and spring (Fang et al., 2005), which agreed with Haas's study (2014). On one hand, most fungal spores in 
the air are thought to come from vegetation rather than soil, and phylloplanes provide more habitats for fungal growth (Picco et al., 2000), for example, urban plants in Beijing flourish only in summer and early autumn, whereas they grow very well in Hangzhou even in early spring and late autumn. On the other hand, the air temperatures during summer and autumn in Beijing are conducive to the germination, growth, and propagation of airborne fungi, whereas all of the seasons, except winter, support atmospheric fungal growth in Hangzhou. Hence, large differences in the seasonal fungal variation between urban areas in the southeast and those in the north of China may arise.

As mentioned above, meteorological parameters critically affect fungal survivability. In the present study, the air temperature was positively correlated with the concentrations of the total fungi, Penicillium, and Aspergillus, and the relative humidity was significantly and positively correlated with the concentrations of the total fungi and Penicillium. Pyrri et al. (2017) reported that the air temperature exerted a consistently strong influence and was the single best predictor of the fungal concentration in the atmosphere. The air temperature was positively correlated with the total fungal count as well as the populations of Cladosporium, Aspergillus, and Alternaria and negatively correlated with the genus Penicillium, whereas the relative humidity was negatively correlated with the populations of the prevalent genera, except Penicillium (Pyrri et al., 2017). Abdel Hameed et al. (2012) discovered that the air temperature and relative humidity were the most predicted variants for airborne fungi. The air temperature was positively and negatively correlated with the concentrations of Aspergillus and Penicillium, respectively, whereas the relative humidity was positively correlated with the concentrations of the total fungi, Aspergillus, and Cladosporium (Abdel Hameed et al., 2012). All of these results indicate that the air temperature and the relative humidity are the most significant meteorological parameters in terms of fungal concentrations in the atmosphere. Notably, the mean concentration of airborne fungi was higher in Beijing (1163 $\left.\mathrm{CFU} \mathrm{m}^{-3}\right)$ than in Hangzhou (848 CFU m${ }^{-3}$ ) (Fang et al., 2005), and a much higher mean bacterial concentration in the atmosphere was also detected in Beijing (2217 CFU m ${ }^{-3}$; Hangzhou: $292 \mathrm{CFU} \mathrm{m}^{-3}$ ) (Fang et al., 2007; Fang et al., 2016), suggesting that microbial concentrations in the air may be much lower in the typical urban landscape of southern China than that of northern China. Firstly, Beijing has a continental monsoon climate with cold dry winters and windy arid springs, which leads to many sandy and dusty days throughout the year. By contrast, Hangzhou's climate is subtropical, so sandy or dusty weather is seldom experienced. According to multiple studies, sand and dust near the ground is one of the main sources of airborne microbes (Polymenakou et al., 2008; Chen et al., 2010; Jeon et al., 2013; Maki, 2014). Secondly, as a whole, urban plants experience better annual growth in Hangzhou than in Beijing due to differences in climate, and volatile secretions released by plants can disinfect bacteria in the air (Xie et al., 1999). Thirdly, Hangzhou is one of the typical tourist cities of southeastern China; it is very clean and often rated as one of the most livable urban areas in the country. All of these factors may directly result in lower concentrations of airborne microbes in Hangzhou than in Beijing.

\section{ACKNOWLEDGEMENTS}

This study was financially supported by the Project of Zhejiang Natural Science Foundation (LY17D050006), and the Project of National Natural Science Foundation of China (No. 81402682), and the Open Fund of State Key Laboratory of Urban and Regional Ecology, Research Center for Eco-Environmental Sciences, Chinese Academy of Sciences (No. SKLURE2015-2-1). The authors also thank the graduate students (Chanjuan Gong) who performed the investigation at different sampling sites in Hangzhou.

\section{REFERENCES}

Abdel Hameed, A.A., Khoder, M.I., Yuosra, S., Osman, A.M. and Ghanem, S. (2009). Diurnal distribution of airborne bacteria and fungi in the atmosphere of Hewan area, Egypt. Sci. Total Environ. 407: 6217-6222.

Abdel Hameed, A.A., Khoder, M I., Ibrahim, Y.H., Saeed, Y., Osman, M.E. and Ghanem, S. (2012). Study on some factors affecting survivability of airborne fungi. Sci. Total Environ. 414: 696-700.

Adhikari, A., Sen, M.M., Gupta-Bhattacharya, S. and Chanda, S. (2004). Airborne viable, non-viable, and allergenic fungi in a rural agricultural area of India: A 2year study at five outdoor sampling stations. Sci. Total Environ. 326: 123-141.

Ariya, P.A., Sun, J., Eltouny, N.A., Hudson, E.D., Hayes, C.T. and Kos, G. (2009). Physical and chemical characterization of bioaerosols - Implications for nucleation processes. Int. Rev. Phys. Chem. 28: 1-32.

Bush, R.K., Portnoy, J.M., Saxon, A., Terr, A.I. and Wood, R.A. (2006). The medical effects of mold exposure. $J$. Allergy Clin. Immunol. 117: 326-333.

Chen, P.S., Tsai, F.T., Lin, C.K., Yang, C.K., Chan, C.C., Young, C.Y. and Lee, C.H. (2010). Ambient influenza and Avian influenza virus during dust storm days and background days. Environ. Health Perspect. 118: 12111216.

Dillon, H.K., Miller, J.D., Sorenson, W.G., Douwes, J. and Jacobs, R.R. (1999). Review of methods applicable to the assessment of mold exposure to children. Environ. Health Perspect. 107: 473-480.

Eduard, W. (2009). Fungal spores: A critical review of the toxicological and epidemiological evidence as a basis for occupational exposure limit setting. Crit. Rev. Toxicol. 39: 799-864.

Fang, Z.G., Ouyang, Z.Y., Hu, L.F., Wang, X.K. and Zheng, H. (2005). Culturable airborne fungi in outdoor environments in Beijing, China. Sci. Total Environ. 350: 47-58.

Fang, Z.G., Yao, W.C., Lou, X.Q., Hao, C.M., Gong, C.J. and Ouyang, Z.Y. (2016). Profile and characteristics of 
culturable airborne bacteria in Hangzhou, Southeast of China. Aerosol Air Qual. Res. 16: 1690-1700.

Fracchia, L., Pietronave, S., Rinaldi, M. and Martinotti, M.G. (2006). The assessment of airborne bacterial contamination in three composting plants revealed siterelated biological hazard and seasonal variations. $J$. Appl. Microbiol. 100: 973-984.

Fröhlich-Nowoisky, J., Pickersgill, D.A., Després, V.R. and Pöschl, U. (2009). High diversity of fungi in air particulate matter. Proc. Natl. Acad. Sci. U.S.A. 106: 12814-12819.

Gao, M., Yan, X., Qiu, T., Han, M. and Wang, X. (2016). Variation of correlations between factors and culturable airborne bacteria and fungi. Atmos. Environ. 128: 10-19.

Garrett, M.H., Rayment, P.R., Hooper, M.A., Abramson, M.J. and Hooper, B.M. (1998). Indoor airborne fungal spores, house dampness and associations with environmental factors and respiratory health in children. Clin. Exp. Allergy 28: 459-467.

Gorny, R.L., Reponen, T., Willeke, K., Schmechel, D., Robine, E., Boissier, M. and Grinshpun, S.A. (2002). Fungal fragments as indoor air biocontaminants. Appl. Environ. Microbiol. 68: 3522-3531.

Haas, D., Habib, J., Luxner, J., Galler, H., Zarfel, G., Schlacher, R., Friedl, H. and Reinthaler, F.F. (2014). Comparison of background levels of culturable fungal spore concentrations in indoor and outdoor air in southeastern Austria. Atmos. Environ. 98: 640-647.

Horner, W.E., Worthan, A.G. and Morey, P.R. (2004). Airand dustborne mycoflora in houses free of water damage and fungal growth. Appl. Environ. Microbiol. 70: 63946400.

Jeon, E.M., Kim, Y.P., Jeong, K., Kim, I.S., Eom, S.W., Choi, Y.Z. and Ka, J.O. (2013). Impacts of Asian dust events on atmospheric fungal communities. Atmos. Environ. 81: 39-50.

Jones, A.M. and Harrison, R.M. (2004). The effects of meteorological factors on atmospheric bioaerosol concentrations-A review. Sci. Total Environ. 326: 151180.

Ju, T.Z., Suo, A.N., Tian, Y.J. and Feng, K.K. (2003). Analysis on aerobiologia in Lanzhou. Ind. Safety Environ. Pollut. 29: 17-19.

Kalyoncu, F. (2010). Relationship between airborne fungal allergens and meteorological factors in Manisa City, Turkey. Environ. Monit. Assess. 165: 553-558.

Kalyoncu, F. and Ekmekçi, S. (2008). Culturable airborne fungi in outdoor environments in Manisa, Turkey. Fresenius Environ. Bull. 17: 844-848.

Kim, K.H., Kabir, E. and Jahan, S.A. (2018). Airborne bioaerosols and their impact on human health. J. Environ. Sci. 67: 23-35.

Li, Y., Fu, H., Wang, W., Liu, J. and Meng, Q. (2015). Characteristics of bacterial and fungal aerosols during the autumn haze days in Xi'an, China. Atmos. Environ. 122: 439-447.

Lin, W. and Li, C. (2000). Associations of fungal aerosols, air pollutants, and meteorological factors. Aerosol Sci. Technol. 32: 359-368.
Macher, J.M. (1989). Positive-hole correction of multiplejet impactors for collecting viable microorganisms. Am. Ind. Hyg. Assoc. J. 50: 561-568.

Maki, T., Puspitasari, F., Hara, K., Yamada, M., Kobayashi, F., Hasegawa, H. and Iwasaka, Y. (2014). Variations in the structure of airborne bacterial communities in a downwind area during an Asian dust (KOSA) event. Sci. Total Environ. 488-489: 75-84

Möller, E.M., Bahnweg, G., Sandermann, H. and Geiger, H.H. (1992). A simple and efficient protocol for isolation of high molecular weight DNA from filamentous fungi, fruit bodies, and infected plant tissues. Nucleic Acids Res. 20: 6115-6116.

O'Gorman, C.M. and Fuller, H.T. (2008). Prevalence of culturable airborne spores of selected allergenic and pathogenic fungi in outdoor air. Atmos. Environ. 42: 4355-4368.

Park, J.H., Cox-Ganser, J., Rao, C. and Kreiss, K. (2006). Fungal and endotoxin measurements in dust associated with respiratory symptoms in a water-damaged office building. Indoor Air 16: 192-203

Picco, A. and Rodolfi, M. (2000). Airborne fungi as biocontaminants at two Milan underground stations. Int. Biodeterior. Biodegrad. 45: 43-47.

Polymenakou, P.N., Mandalakis, M., Stephanou, E.G. and Tselepides, A. (2008). Particle size distribution of airborne microorganisms and pathogens during an intense African dust event in the Eastern Mediterranean. Environ. Health Perspect. 116: 292-296.

Pyrri, I. and Kapsanaki-Gotsi, E. (2017). Functional relations of airborne fungi to meteorological and pollution factors in a Mediterranean urban environment. Fungal Ecol. 30: $48-54$.

Saito, A., Takatori, M., Takatori, K. and Taniguchi, M. (2015). Transition of airborne fungi during 20-years from 1993 to 2013 in Sagamihara. Areruqi 64: 13131322.

Salonen, H., Duchaine, C., Mazaheri, M., Clifford, S. and Lappalainen, S. (2015a). Airborne viable fungi in school environments in different climatic regions-A review. Atmos. Environ. 104: 186-194.

Salonen, H., Duchaine, C., Mazaheri, M., Clifford, S. and Morawska, L. (2015b). Airborne culturable fungi in naturally ventilated primary school environments in a subtropical climate. Atmos. Environ. 106: 412-418.

Sesartic, A. and Dallafior, T.N. (2011). Global fungal spore emissions, review and synthesis of literature data. Biogeosciences 8: 1181-1192.

Sesartic, A., Lohmann, U. and Storelvmo, T. (2013). Modelling the impact of fungal spore ice nuclei on clouds and precipitation. Environ. Res. Lett. 8: 4029.

Shelton, B.G., Kirkland, K.H., Flander, W.D. and Morris, G.K. (2002). Profiles of airborne fungi in buildings and outdoor environments in the United States. Appl. Environ. Microbiol. 68: 1743-1753.

Stark, P.C., Celedón, J.C., Chew, G.L., Ryan, L.M. and Burge, H.A. (2005). Fungal levels in the home and allergic rhinitis by 5 years of age. Environ. Health Perspect. 113: 1405-1409. 
Tang, J.W. (2009). The effect of environmental parameters on the survival of ariborne infectious agents. J. R. Soc. Interface 6: 737-746.

Wang, W., Ma, X., Ma, Y., Mao, L., Wu, F., Ma, X., An, L. and Feng, H. (2011). Molecular characterization of airborne fungi in caves of the Mogao Grottoes, Dunhuang, China. Int. Biodeterior. Biodegrad.65: 726-731.

White, T.J., Bruns, T., Lee, S. and Taylor, J. (1990). Amplification and direct sequencing of fungal ribosomal RNA genes for phylogenetics. PCR protocols: A guide to methods and applications. Academic Press, New York, pp. 315-322.

Xie, H.L., Li, S.R., Yuan, X.Y., Liu, G.W., Gao, X.M.,
Cao, Y. and Jia, J. (1999). Study on the disinfection of plant volatile secretion to the microorganism content in the air. J. Henan Agric. Univ. 33: 127-133 (in Chinese).

Zuraimi, M.S., Fang, L., Tan, T.K., Chew, F.T. and Tham, K.W. (2009). Airborne fungi in low and high allergic prevalence child care centers. Atmos. Environ. 43: 23912400 .

Received for review, February 4, 2018 Revised, September 29, 2018 Accepted, November 12, 2018 